\title{
APROXIMACIÓN A LA POESÍA ELECTRÓNICA ESCRITA POR MUJERES EN ESPAÑOL: BELÉN GACHE Y ALEX SAUM ${ }^{1}$
}

\author{
AN APPROACH TO ELECTRONIC POETRY \\ WRITTEN BY WOMEN IN SPANISH: BELÉN GACHE \\ Y ALEX SAUM
}

\section{Laura LOZANO MARÍN}

Universidad de Granada

lozanomarin@ugr.es

\begin{abstract}
Resumen: El propósito de este artículo es estudiar una serie de características comunes de la literatura y poesía electrónica y, a partir de estas denominaciones, analizar cómo funcionan las creaciones electrónicas y poéticas de escritoras contemporáneas como son Belén Gache y Alex Saum. Asimismo, en este análisis se establecerán las diferencias y elementos comunes de ambas poetas.
\end{abstract}

Palabras clave: Humanidades digitales. e-poesía. Poesía electrónica. Belén Gache. Alex Saum.

\footnotetext{
${ }^{1}$ Este trabajo es resultado del proyecto "La configuración del patrón poético español tras la instauración de la democracia: relaciones literarias, culturales y sociales" (FFI201680552-P), financiado por el Ministerio de Economía y Competitividad / FEDER.
} 


\begin{abstract}
The purpose of this article is to study a series of common characteristics of the literature and electronic poetry and to analyze how the electronic and poetic creations of contemporary writers such as Belén Gache and Alex Saum work. Also, in this article the differences and common elements of both poets will be studied.
\end{abstract}

Key Words: Digital humanities. e-poetry. Electronic poetry. Belén Gache. Alex Saum

\title{
1. POESÍA ELECTRÓNICA: UNA PARTE DE LAS HUMANIDADES DIGITALES
}

Los cambios tecnológicos son inseparables de los cambios sociales y culturales, así, con el auge y desarrollo de las tecnologías digitales asistimos a nuevas formas de leer, comprender y escribir poesía. Surgen nuevas formas de textualidad como la poesía generada por ordenador, también denominada poesía electrónica, e-poesía, poesía digital o ciberpoesía. Como explican María Engberg y Jay David Bolter (2011) en las últimas décadas la literatura electrónica ha pasado de centrarse únicamente en el hipertexto y en los generadores automáticos de texto para desarrollar un amplio rango de nuevas formas de literatura electrónica, como son, entre otras, la e-poesía, los codeworks, las ficciones social media o las narrativas hipermedia.

Cabe entonces preguntarse qué es la literatura electrónica que engloba a la e-poesía. Joan-Elles Adell (2004: 138), afirma que la literatura electrónica es una literatura en fase de formación y en continuo desarrollo, por lo que no se podría formular una definición concreta y exacta sobre qué es la literatura y poesía electrónica. Sin embargo, hay definiciones de estudiosos de esta literatura que intentan aportar una idea general sobre este concepto, es el caso de Philippe Bootz, poeta electrónico francés co- 
fundador en 1989 del grupo L.A.I.R.E. ${ }^{2}$, que define la literatura digital en Les Basiques: la littérature numérique de la siguiente forma:

Nous désignerons par "littérature numérique" toute forme narrative ou poétique qui utilise le dispositif informatique comme médium et met en oeuvre une ou plusieurs propriétés spécifiques à ce médium (Bootz, 2006).

La definición de Bootz puede generar una pregunta que muchos críticos se han planteado antes; ¿es la e-literatura cualquier texto literario que aparece en la pantalla del ordenador o cualquier otro dispositivo digital? La respuesta sería negativa ya que la literatura electrónica es explícitamente creada y diseñada para su lectura, edición y uso digital y se aprovecha de las ventajas que le ofrece esta tecnología (Sánchez-Mesa, 2010: 140). Por tanto, en esta línea, más actual y acertada es la definición de literatura electrónica que ofrece la Electronic Literature Organization: "refers to works with important literary aspects that take advantage of the capabilities and contexts provided by the stand-alone or networked computer".

En el caso de la e-poesía, los críticos y estudiosos han intentado definir una serie de características generales que se dan con frecuencia en este tipo de piezas poéticas. Así, Begoña Regueiro (2012: 239-240) condensa las características que Bootz aplica a la poesía electrónica en sus diferentes artículos y que definirían de alguna forma las bases de la e-poesía. Establece que la literatura electrónica se debe entender como un proceso generador y no simplemente como un resultado obtenido. A su vez, defiende que la temporalidad irrumpe en lo escrito, lo que asemejaría a este tipo de poesía a las artes vivas. Por otro lado, explica que se produce un

\footnotetext{
${ }^{2}$ Grupo formado por Philippe Bootz, Frédéric Develay, Jean-Matie Dutey, Claude Maillard y Tibor Papp. A su vez, este grupo se vincula a la revista Alire, que fue la primera revista regular de poesía digital del mundo (Vuillemin, 2005: 174) en la que publicaban creaciones digitales y textos teóricos sobre literatura digital.
} 
desplazamiento del concepto tradicional de obra, ya que la parte de la programación, normalmente, no está destinada a la lectura, pero sí que entraría en el proceso artístico y creador. Otra de las características fundamentales que Bootz señala es la interactividad. Este término es para algunos críticos objeto de controversia, puesto que la interactividad puede establecerse de diferentes formas y en mayor o menor medida, sin embargo con el mero hecho de que el lector inicie el poema electrónico clicando y navegando por la pantalla ya implica una mínima interacción con el poema y el medio informático. En esta línea, el poeta francés también menciona el transitorio observable para denominar a los elementos que aparecen en la pantalla en tiempo real producidos por el programa y estipula que pueden existir diferentes transitorios observables según la lectura que se esté haciendo, ya que, en multitud de ocasiones, la poesía electrónica permite más de una lectura según la interacción que el lector aplique en esa pieza poética.

Asimismo, en este tipo de poesía la materialidad con la que se trabaja es totalmente distinta, ya que esta es el medio digital, así y como apunta Laura Borrás (2005: 50), el texto establecería un compromiso con la materialidad de su medio haciendo que el contenido y la forma que lo aloja no puedan entenderse si están separados. Bootz (1999) a la hora de estudiar y analizar este tipo de literatura, afirma que los medios informáticos que se utilizan para su creación modifican la manera de concebir la propia creación literaria en su totalidad y, por tanto, estos medios no solo contribuirían en la construcción y difusión de esta literatura. Esta noción erradicaría las ideas más conservadoras de la crítica que establecen que las nuevas tecnologías aniquilan la literatura, ya que lo que pretenden es transformarla con nuevas realizaciones digitales, con nuevas formas de lectura y de creación.

En esta línea, Adell (2004: 142) establece dos planteamientos que se deben tener en cuenta en el estudio de la e-poesía. El primero es la concepción de que la lectura de un texto electrónico generado por ordenador rompe con la tradicional lectura de textos en formato impreso. La acción de leer sigue consistiendo en captar y percibir los signos que ha desarrolla- 
do el escritor, pero la forma en que se lee esta escritura es una experiencia radicalmente nueva en la que se supera el formato fijo de la página. De hecho, y como apunta Alex Saum (2017), estos textos perderían su significado expresivo si se imprimieran, puesto que son textos creados con el ordenador para ser leídos en el ordenador como ocurre con la mayoría de literatura electrónica. El segundo planteamiento tiene que ver con que "la poesía electrónica no es únicamente una poética de la pantalla" (Adell, 2004: 142), sino que es también una poética de la programación; esto quiere decir que la tarea del escritor no conlleva únicamente crear un texto, sino también programarlo, por lo que, coincidiendo con los argumentos de Bootz, esta actividad entraría dentro del proceso creativo del poema electrónico.

Otra característica que varios estudiosos y críticos de las Humanidades Digitales otorgan a la e-poesía es su herencia e inspiración de las vanguardias de principio de siglo XX, puesto que "los ideales de las vanguardias históricas se cumplen en las vanguardias digitales" (Molinuevo, 2006: 20). La exploración de nuevos medios tecnológicos para realizar una escritura experimental del poema asemeja este tipo de obras a las de movimientos de vanguardia como el Futurismo, Cubismo, Constructivismo o Dadaísmo, pero creando nuevas convenciones de experimentación:

All cybertextual works are in a very concrete sense experimental writing. First of all, the authors are experimenting with the new media, trying to find out what is possible in digital textuality, what are the limits of literary expression in programmable media. This is a question not so much of experimenting to break established conventions, as of experimenting in an attempt to create new conventions. Since the new digital technology plays such a crucial role in cybertextuality, we may call the works in this emerging field as "technological avant-garde" (Koskimaa, 2010: 127). 
Como las vanguardias, la e-poesía realiza combinaciones de escritura e imagen pero en un nivel superior gracias al uso e implemento de tecnologías digitales en su creación, por lo que es según Heidrun Krieger "el ejemplo más radical del juego cooperativo entre escritura, imagen, sonido y movimiento hasta ahora" (2012: 184). En este punto cabría destacar el temor que algunos críticos experimentan ante una posible sustitución de la palabra escrita por la imagen y por el sonido, sin embargo sería la combinación de todos estos elementos en este tipo de poesía lo que la acerca a una obra de arte total (Krieger Olinto, 2012: 186).

Pero se debe tener en cuenta que la e-poesía no tiene solo un importante valor artístico sino que también puede tener un gran valor social. La digitalización afecta a la comprensión de nuestra experiencia cotidiana, por lo que la poesía electrónica funciona como vehículo de expresión de la nueva sociedad digitalizada, funciona como una nueva forma de producción cultural que puede ser reivindicativa y tener elementos de denuncia social como ocurre en algunas piezas de las poetas electrónicas Belén Gache y Alex Saum.

\section{LA E-POESÍA DE BELÉN GACHE Y ALEX SAUM}

Como ocurre con la literatura que no es digital, en la e-poesía hay una menor representación y visibilidad para las piezas poéticas que escriben mujeres. Luce Irigaray (1985: 221) explica que lo masculino funciona como el estándar universal y la forma privilegiada en nuestros sistemas de representación relegando lo femenino a un segundo - y poco valoradoplano. Sin embargo, dentro del panorama de la e-poesía, cada vez más mujeres están ocupando su espacio y escriben poemas electrónicos como Belén Gache y Alex Saum.

Belén Gache es una escritora argentino-española que, desde 1996, ha centrado una gran parte de su trabajo en la creación de literatura experimental y poesía electrónica, sobre la que también ha teorizado. Las 
dos colecciones poéticas que aquí analizaremos son Wordtoys (2006) y Góngora Wordtoys (2011). Ambas obras se presentan imitando el formato tradicional de libro, compuesto por capítulos-poemas e índice. De hecho, el lector debe interactuar con el ratón y clicar en las páginas para poder pasarlas imitando y reproduciendo el movimiento y sonido particular que hacen las hojas de un libro al moverse. De entrada y solo con el título de ambas obras, el lector toma conciencia del carácter lúdico y de juego que va a caracterizar a la obra de Gache y que estaría en relación con esa herencia vanguardista de la e-poesía.

Así, en Wordtoys (2006) la interfaz principal muestra la imagen animada de una mujer haciendo burbujas que contienen el nombre de la obra. Al clicar sobre la imagen se abre una nueva interfaz que muestra el formato tradicional de libro. Este está compuesto por trece capítulospoemas que en formato hipermedia "poseen una importante presencia de intertextualidades, como un homenaje tecnológico a la tradición artística y literaria, con especial ímpetu en las prácticas vanguardistas" (Corral Cañas, 2015) y se titulan: "El jardín de la emperatriz Suiko", "El idioma de los pájaros", "Mariposas-libro", "Southern Heavens", "Procesador de textos rimbaudiano", "Phone readings", "Los sueños", "Poemas de agua", “¿Por qué se suicidó la señorita Chao?”, "Veintidós mariposas rosas”, "Mujeres vampiro invaden colonia de Sacramento", "Canon occidental", "Escribe tu propio Quijote" y "La biblioteca". Todas estas piezas poéticas están, a su vez, precedidas de una pequeña explicación introductoria, una especie de manual de uso con instrucciones para el lector.

Además de estar latentes las características generales de la e-poesía que ya se han desarrollado en el apartado anterior, Gache les imprime otros atributos. Uno de ellos es el afán lúdico que ya adelantábamos; con algunos de sus poemas la poeta plantea juegos al lector como es el caso de "Escribe tu propio Quijote" donde el receptor debe escribir su versión del libro, pero no importa lo que escriba en el ficticio procesador de texto porque siempre aparecerá en la pantalla el inicio de la obra de Cervantes. En la introducción a esta pieza, Gache expone que se inspira en la experiencia 
de Do it yourself flowers de Andy Warhol y también “evoca la problematización de la autoría del Quijote" (Corral Cañas: 2015), desde la obra de Cervantes, donde juega con la técnica del manuscrito hallado firmado por Cide Hamete Benengeli, hasta el cuento de Borges Pierre Menard, autor del Quijote, donde el escritor simbolista intenta re-escribir el libro de Cervantes. Así como en el cuento de Borges, Gache reflexiona con este poema electrónico sobre temáticas como la identidad fija de un texto o la autoría original. A su vez, con este poema la escritora incita al lector a plantearse que la experiencia de lectura y escritura "se ve modificada por el uso de nuevos medios y el uso de una materialidad diferente que genera otros contextos de recepción para una misma obra" (Gainza, 2014: 34).

Como se puede comprobar en Wordtoys hay todo un diálogo con otras obras literarias canonizadas, se trata de una característica frecuente en la literatura electrónica que es la del enciclopedismo o collage que la propia Gache describe en el libro donde teoriza sobra la literatura electrónica, Escrituras nómades, y con la que se refiere "a la posibilidad de tomar elementos preexistentes e integrarlos en una nueva creación, con lo que hace hincapié en la polifonía y en la intertextualidad" (Regueiro Salgado, 2012: 241). Así, además de la interacción constante que necesita cada poema electrónico para poder leerlo, Gache requiere que el receptor sea consciente y pueda identificar las diferentes intertextualidades para que la interpretación de la pieza sea lo más completa posible. "Poemas de agua" es un claro ejemplo de intertextualidad. Al clicar en este capítulo-poema, aparece una interfaz con la imagen de un lavamanos compuesto por dos grifos, en los que al pulsarlos una lluvia de letras cae a la pila donde se unen para formar citas — cada una en su idioma originario - de autores consagrados como Baudelaire, Ashbery, Quevedo, Borges o Verlaine entre otros muchos.

Otro poema en el que se encuentra claramente esta intertextualidad es en "El idioma de los pájaros". La introducción al poema electrónico comienza de la siguiente forma: 
Una vez, un ruiseñor mecánico alegró las horas del Emperador de la China. Su pequeño cuerpo cubierto de láminas de oro y de diamantes guardaba en su interior un delicado mecanismo de relojería que le permitía interpretar las composiciones musicales más hermosas, una y otra vez (Gache, 2006).

Continúa desarrollando este tema de los pájaros re-citadores aludiendo a otros escritores como Anaximandro, Apolonio de Tiana, Esopo, Farid Uddin Attar e Italo Calvino, hasta que Gache da las claves de esta pieza poética:

Los pájaros de "El idioma de los pájaros" son máquinaspoetas. En este sentido, comparten con el ruiseñor mecánico, en primer lugar, la paradoja de combinar una fragilidad extrema con una armadura rígida y monstruosa. También comparten el hecho de estar programados para re-citar palabras. ¿Acaso las palabras no son siempre ajenas? (Gache, 2006).

Así, al iniciar el poema electrónico aparece en la pantalla cinco pájaros diferentes que al clicar en cada uno de ellos recitan poemas de poetas reconocidos, cuyos protagonistas son precisamente aves. Se pueden oír de sus picos los versos — cada uno en su idioma - de "Leda", de Rubén Darío, "Volverán las oscuras golondrinas", de Gustavo Adolfo Bécquer, "Le paon", de Guillaume Apollinaire, "The raven", de Edgar Allan Poe, y "Le cygne", de Charles Baudelaire. Al pulsar todos los pájaros a la vez se crea un coro donde se confunden los poemas creando una jaula de lenguaje: "Esta es la trágica canción de los pájaros de 'El idioma de los pájaros': cuanto más cantan, más irremediablemente prisioneros quedarán de la jaula del lenguaje" (Gache, 2006). En este poema, Gache denuncia al lenguaje como mecanismo de control que nos encierra en ciertas for- 
mas de recepción. Asimismo, en "El idioma de los pájaros" la escritora plasma la importancia de la máquina a la que hace guiños en la introducción al poema electrónico y en las voces de los pájaros que están alteradas por moduladores de voz, lo que transmite la sensación de automatismo y tono mecánico que lo aleja de la calidez de la voz humana. En esta línea cabe destacar la función principal que tiene la oralidad en este poema, ya que, una vez iniciada esta pieza electrónica, no aparece ningún texto escrito, solo se puede interactuar con los pájaros y su canto re-citando. En "Phone readings" también está presente esta oralidad, en esta pieza poética encontramos doce teléfonos que, al clicarlos, una voz femenina relata cortas instrucciones para convertir lágrimas en perlas o colas de pavos reales en abanicos japoneses, así como cuenta pequeñas historias como la del manual de lavado de cerebros. En "Canon occidental" y en "Southern Heavens" continúa la oralidad y las voces moduladas, de igual manera ocurre con el poema "Los sueños", sin embargo, en esta pieza aunque las voces son el elemento principal, también aparece en la pantalla el texto que están recitando las voces cuando se mueve el cursor por el paisaje dado.

En Wordtoys hay poemas en los que la interacción del lector es aún más necesaria que simplemente clicar y mover el cursor, esto ocurre en "Mariposas-libro" donde Belén Gache invita a que se le envíen citas literarias o científicas:

Al igual que Linneo clasificaba sus insectos en diferentes clases, colores, tamaños; al igual que un entomólogo caza mariposas y las ordena luego clavando sus cuerpos con alfileres, aquí coleccionaré citas-mariposa. (Teniendo en cuenta, además, que las mariposas se parecen topológicamente a los libros) (Gache, 2006).

Así, al pulsar cada una de las mariposas que aparecen en la pantalla estas se tornan en una de las citas que han sido enviadas, desarrollando así la idea de enciclopedismo y la noción de creación colectiva, característica 
que se encuentra además en "Procesador de textos rimbaudiano" y "La biblioteca". En esta última composición, Gache en su introducción inicial reflexiona sobre la importancia de las portadas de los libros: "Las tapas de los libros resguardan y a la vez preceden y presentan las páginas del mismo, creando un horizonte de expectativas en el lector" (Gache, 2006). Explica que a partir de la tapa intuimos, imaginamos, prejuzgamos un libro y hasta anticipamos su lectura, por lo que invita al lector en este poema a escribir reseñas de libros partiendo de diversas portadas inventadas.

Otra característica muy presente en los poemas electrónicos de Belen Gache es el nomadismo, que estaría en relación con los transitorios observables que Bootz definía. Con este término la autora hace referencia a "la deconstrucción de la idea de una trama única, dado que los diferentes recorridos posibles dan lugar a una lectura múltiple” (Begueiro Salgado, 2012: 241), simula la actitud de un viajero que se desplaza por una nueva ciudad y va eligiendo rutas alternativas para llegar a diferentes lugares, de igual forma actúa el lector del poema electrónico que dependiendo de su interacción realiza lecturas diferentes.

En su siguiente serie de poesía electrónica, Góngora Wordtoys (2011), el lector encuentra un giro de tuerca de esas palabrasjuguete de Belén Gache. En esta obra, la escritora homenajea al poeta barroco recreando de forma lúdica textos de las Soledades, por lo que la intertextualidad está muy presente en toda la obra. Gache en el "Prefacio" de esta obra explica el paralelismo que hay entre el barroco y la escritura de Góngora en las Soledades con la literatura digital:

Los escritores y artistas del barroco habitaban un mundo desengañado de apariencias y falsedades. Este era el mundo de Góngora, cuyo trabajo con el lenguaje de Soledades ha sido comparado con el de Kepler: así como este último puso de manifiesto que la trayectoria de la Tierra respecto del Sol era elíptica y no circular y "descentró" la cosmogonía del pensamiento renacentista clásico, nuestro poeta realizó 
una elipsis metafórica donde seres y objetos perdian su centro en la representación y permanecían perdidos tras el abigarramiento de los signos. El Góngora de Soledades, desclasado, desterrado, con su postura periférica respecto a la Academia de la Corte, escribe desde un margen artificioso y críptico (Gache, 2011).

Así, Gongora Wordtoys se compone de cinco poemas: "Dedicatoria espiral", "En breve espacio mucha primavera", "Delicias del Parnaso", "El llanto del peregrino" y "El arte de la cetrería", presentándonos un universo plagado de espirales, pliegues y laberintos del lenguaje. Si en el anterior Wordtoys destacábamos el carácter lúdico de sus piezas poéticas, en este conjunto Gache lo lleva a un nivel superior. La interfaz principal muestra la imagen de un paisaje imitando el estilo de los videojuegos de 8 bits $\mathrm{y}$ al clicar sobre esta imagen se abre una nueva interfaz que muestra el formato tradicional de libro. La misma estética de videojuego de 8 bits la mantiene en el poema "Delicias del parnaso" que es, literalmente, un juego — o incluso podríamos decir videojuego — donde en cada pantalla se presentan dos maneras diferentes de terminar una estrofa de las Soledades: una es incorrecta y la otra es la compuesta por Góngora. El desafío del lector es descubrirla y, emulando al genio barroco, alcanzar el Parnaso de los poetas españoles, donde "La cumbre del Parnaso simboliza el cénit del prestigio literario y allí, los genios escritores que ingresan al canon se vuelven inmortales y conviven con los dioses" (Gache, 2011). Para ello, la escritora nos brinda tres oportunidades y si fallamos tendremos que empezar de nuevo el juego. Si por el contrario acertamos los tres versos aparece ante nosotros el cuadro de Rafael Sanzio, El parnaso.

De igual forma en "El llanto del peregrino" el lector asiste ante un poema electrónico que se asemeja a un videojuego de plataformas donde el peregrino es un pequeño monigote que movemos con las flechas de dirección del teclado por las palabras del fragmento seleccionado de las Soledades, "Llanto del peregrino". Gache establece así un juego 
lingüístico-visual, presenta el texto como un poema laberinto, tomando la idea del barroco y de Borges, y "recrea el texto como una metáfora de la búsqueda del hombre que parece caminar por su vida a ciegas a través de tortuosos caminos en busca su pasado, su destino y su sentido" (Gache, 2011). De este modo, el peregrino recorre, nómada, el complejo camino de sus circunstancias guiado por el lector que transita por los versos de Góngora.

En "Dedicatoria espiral" la escritora reproduce el texto de la dedicatoria al Duque de Béjar y explica en la introducción al poema electrónico que en las Soledades el texto se presenta como en una espiral, tangencial, centrífugo y centrípeto, pleno de movimiento, inconcluso y abierto. Así, cuando accionamos el poema, aparece en la pantalla una espiral de letras que contienen esta dedicatoria y que giran hacia un lado o hacia otro dependiendo de por dónde desplacemos el cursor. En "Breve espacio mucha primavera" la escritora expone los versos de Góngora de nuevo de una forma especial. En esta ocasión lo hace a través de ventanas emergentes o рор ups, donde al clicar en una primera palabra desencadena una serie de pop ups que contienen el resto del poema. Así lo explica y relaciona con el barroco en la introducción a la pieza poética:

Recordando al pliegue barroco-leibniziano-deleuziano, en un despliegue barroco constante, los signos proliferan al infinito, de manera incontrolable. Mientras tanto el mundo se pierde tras los signos, abigarrados, amorfos, oscuros, enmascarados, anamórficos y metamórficos. Todo se pliega, se despliega y se repliega y el mundo estalla en la multiplicidad de todas sus representaciones posibles (Gache, 2011).

Finalmente, en la última pieza poética de Góngora Wordtoys, titulada "El arte de la cetrería", encontramos, de nuevo, los pájaros recitadores. En este caso son ocho pájaros diferentes que se corresponden 
con las aves asesinas que son citadas por Góngora en el último fragmento de las Soledades. En el poema electrónico las aves aparecen dispuestas en un pentagrama musical y, con la voz modificada con un procesador de voz, recitan los versos en las que se las nombra. Aúna, de nuevo, la oralidad y la presencia de la máquina. De este modo, y como explica Gache, en Góngora Wordtoys, "al igual que en la poesía del barroco, encontraremos aquí máquinas, despliegue visual y artificios” (Gache, 2011). Tanto en Wordtoys como en Góngora Wordtoys, Gache vincula la tradición con la modernidad técnica y digital, dando la oportunidad al lector de jugar con la lectura de la obra.

En el caso de la poesía electrónica de Alex Saum se encuentran ciertas diferencias en relación con la de Belén Gache. Alex Saum-Pascual es profesora en la Universidad de California, Berkeley, donde imparte asignaturas de literatura y cultura españolas y literatura electrónica. Analizaremos dos de sus colecciones bilingües (español e inglés) y multimedia pertenecientes a su proyecto \#SELFIEPOETRY. Una primera diferencia entre ambas poetas reside en el idioma, Gache desarrolla su obra principalmente en español y Saum lo hace de forma bilingüe, ya que como ella misma explica, la poesía electrónica se trata de un tipo de literatura que se mueve fácilmente entre los medios, pero también entre las tradiciones lingüísticas y los idiomas (Saum, 2017). Asimismo, al combinar dos idiomas le añade cierto carácter lúdico a su obra y la proyecta hacia un público más amplio.

La primera colección, \#SELFIEPOETRY: Fake Art Histories \& the Inscription of the Digital Self, explora, según explica Saum, dos ideas interrelacionadas: la falsedad tras las historias literarias y artísticas, y nuestra (i)legitimidad a la hora de intervenir en ellas para crear narrativas teleológicas que nos expliquen su evolución. Esta colección, que formó parte de exposición Code/Switch (Woman Made Gallery) en Chicago en 2016, consta de ocho poemas: "Dreamtigers tigers tigers", "Futurismo", "The Democratic Value of Art Making", "Sensitive But Unclassified (SBU)", "No Weekend Wi-Fi, un cuadro costumbrista (US of A)", "The 
Measure of All Things", "Pupila Romántica” y “City of Eléi”. Estos cuestionan cómo el Yo puede reinterpretarse dentro de una selección un poco vaga, y poco ortodoxa, de movimientos literarios en español e inglés. Alex Saum (2015) explica que otra faceta que le intriga e intenta explorar con estos poemas es la asignación de los roles atribuidos al productor y consumidor de arte, que tradicionalmente han estado separados y que ahora comienzan a mezclarse y difuminar sus límites gracias, precisamente, a las representaciones artísticas en los medios digitales. En esta línea Saum apunta que la subjetividad y la representación de los consumidores se ha convertido en una forma particular de señalización individual que convierte al sujeto en un objeto de representación y de (auto)distribución masivo. Así, el Yo y la propia imagen fotográfica del Yo, aparecen en diferentes plataformas digitales, inscribiéndose en el espacio y tiempo de la web y manifestando la obsesión actual por nuestras propias caras. Con esta explicación cobra sentido el título de estas series, \#SELFIEPOETRY, ya que presenta algunas formas en que la inscripción del Yo - en la manifestación digital paradigmática actual como es el selfie- puede reinterpretarse frente a una selección de tendencias artísticas y literarias.

Al iniciar la serie de poemas, la escritora avisa al lector de que las piezas poéticas que va a leer y con las que va a interactuar tienen una existencia precaria ya que están alojadas en una plataforma web por lo que "they depend completely on external forces, they barely hang on to the shaky web. They have a life of their own, being completely out of my creative control". Como explica Adell, "En la literatura electrónica el soporte, por su propia naturaleza es inestable, y uno de los trabajos de estos escritores es precisamente, explotar lo máximo posible esta especificidad" (Adell, 2004: 142), y así lo hace Alex Saum, que además pone de manifiesto la precariedad de los medios digitales y la representación online.

Como ocurría con la poesía electrónica de Belén Gache, en la obra poética de Alex Saum hay un gran despliegue de intertextualidades. Se puede comprobar en el poema "Dreamtiguers tiguers tiguers", que es un homenaje a Jorge Luis Borges. Al accionar el poema aparece una pan- 
talla en la que comienza a sonar la lectura de Dreamtiguers - recogido en el libro de Borges, El hacedor - tanto en inglés como en español. La grabación de voz se repite interminablemente en ambos idiomas y se ve interrumpida por un vídeo de YouTube que trata sobre los últimos tigres salvajes en la Tierra. A su vez, en la pantalla aparece un fragmento de la obra de Borges en inglés y se superponen varias copias de un selfie de Saum que muestra su rostro parcialmente oculto por una fotografía de un tigre corriendo.

En el poema "Pupila Romántica" hay una clara referencia a Gustavo Adolfo Bécquer. En él, Saum reinterpreta la famosa "Rima XXI" del poeta romántico para hacerla sobre ella misma. En la pantalla aparece una fotografía de la pupila de la escritora que está animada y produce un mecánico y artificial parpadeo. Navegando por el poema se encuentra hasta tres veces esta imagen y el siguiente corto texto: "Bécquer dijo que la poesía era yo. Clavando mi pupila en tu pupila azul”. Con este texto asistimos a una inversión de papeles; en su poema Bécquer establece que él es el poeta mientras que la mujer, musa por antonomasia, es la poesía. En este poema electrónico, Saum, siguiendo a Bécquer, es la representación de la poesía que pone de manifiesto con el selfie de su medio rostro pero, además, ella es la poeta que crea esta pieza.

$\mathrm{Al}$ accionar "The Measure of All Things" se muestra un fondo que tiene la imagen de El hombre de Vitruvio de Leonardo da Vinci y, sobre la imagen se repite, la frase "Your Digital Presence is the Measure of All Things". A su vez, sobre el texto y la imagen se despliegan una serie de vídeos de YouTube en los que aparece Alex Saum recitando en español, y en distintos tiempos, el "Soneto XXIII" de Garcilaso de la Vega. Al explicar este poema, Saum va a contraponer la creencia renacentista en el cuerpo humano como una antología del universo, con la representación actual del selfie en la web:

According to the Encyclopaedia Britannica online, "Leonardo envisaged the great picture chart of the human body he had 
produced through his anatomical drawings and Vitruvian Man as a cosmografia del minor mondo (cosmography of the microcosm)." The Renaissance belief in the human body as an analogy of the universe is confronted with today's representation of the selfie in the Web (Saum-Pascal, 2015).

En el poema electrónico "Futurismo" hay una clara referencia a los movimientos de la vanguardia histórica. Saum (2015) explica que el futurismo, que rápidamente se asocia con ideas como velocidad, máquinas, progreso, guerra e industrialismo, nos lleva de vuelta a un momento concreto de la historia occidental, caracterizado por revoluciones, tanto políticas como mecánicas, y manifiestos artísticos. Cuando escribía este poema Saum estaba leyendo Digital Memory and the Archive de Wolfgang Ernst donde expone que los medios técnicos registran el tiempo y actúan como una máquina del tiempo, como un cortocircuito entre tiempos históricamente separados. Así, Saum relaciona la idea de que las máquinas cortocircuiten la historia con la capacidad poética de la performatividad digital para llevar el pasado a la misma realidad reproductiva del presente. En este poema aparece un selfie de la escritora junto a una foto de un poema escrito a mano superpuesto sobre otras imágenes de engranajes y piezas de motor. El final del poema se rompe en una espiral animada que gira mientras la voz de Saum recita dicho poema junto con sonidos de máquina.

"Sensitive But Unclassified (SBU)" es un poema electrónico que tiene que ver con la inmigración en los Estados Unidos y con Walt Whitman y su interpretación de la identidad y la sexualidad estadounidense. Varias copias en movimiento de la fotografía que Saum utilizó para pedir su visado inundan la pantalla mientras una voz masculina lee la entrada de la Wikipedia, de la que también hay una imagen, o captura de pantalla, en el poema sobre Walt Whitman.

Más interacción del lector requiere el poema "The Democratic Value of Art Making" donde Saum reutiliza una foto de Instagram sobre la que superpone dos oraciones que cruzan la pantalla y dicen así: "No todos 
podemos ser poetas. Pero todos tenemos valor literario". Desperdigados por la pantalla, hay además, una serie de botones que el lector puede pulsar activando la lectura de las palabras que se mueven y también puede reproducir, pulsando esos botones, los latidos de un corazón.

Finalmente, en los poemas "No Weekend Wi-Fi, un cuadro costumbrista (US of A)" y "City of Eléi” la interacción se limita a activar el poema y navegar por la pantalla de este, en la que se combina texto, sonido e imagen.

La segunda serie que escribe Alex Saum de su colección \#SELFIEPOETRY se titula WOMEN \& CAPITALISM. Saum expone que esta serie de poemas explora la relación entre las mujeres y su percepción dentro de la estructura (neoliberal) de deseo contemporáneo. Los textos surgen de la experiencia de Alex Saum de vivir durante casi una década en los Estados Unidos y su uso y abuso de las redes sociales. A diferencia de la colección anterior, esta serie está sin terminar, sujeta al cambio constante y condenada a no ser completada jamás. De esta serie destacan poemas como "24_7" que fue finalista en Print Screen 2016, el festival internacional de arte y cultura digital de Israel. Al iniciar este poema aparece en la pantalla una serie de vídeos de YouTube en los que aparece Saum dando muestras de cansancio, de sueño y bostezando. A su vez, diseminadas junto con los vídeos, hay una serie de páginas del libro de Jonathan Crary, 24/7: Capitalismo tardío y el fin del sueño, libro que analiza las consecuencias negativas de los procesos productivos del capitalismo del siglo XXI sobre la capacidad de atención de la sociedad. Una de las consecuencias es la falta de sueño, el robo de sueño de estos sistemas de consumo que obligan al individuo a producir y trabajar las 24 horas del día, los 7 días de la semana. Es precisamente esta privación del sueño la que plasma Saum en su poema electrónico.

En "Vida perra" se encuentra un GIF y los siguientes versos que reivindican el propio trabajo de Saum como poeta en este poema electrónico: 


\author{
But \\ not \\ really, \\ this is \\ just \\ a computer program \\ that I wrote \\ with my girl hands \\ and my girl fingers \\ and my girl nails \\ and my girl arms \\ but \\ not really \\ this all \\ son solo palabras \\ y cables \\ $y$ numeros \\ $y$ amor \\ todo esto \\ sin tilde ni acento $\mathrm{ni}$ \\ tampoco mucho amor.
}

Otro poema donde se reivindica el trabajo y la presencia de la mujer en el mundo de la informática y las tecnologías digitales es en "Enciclopedia Mecánica", donde aparece una captura de pantalla de la Wikipedia con la entrada en inglés sobre Ángela Ruiz Robles que inventó la primera propuesta de enciclopedia mecánica. Sobre este fondo de la Wikipedia hay una serie de imágenes animadas que muestran el prototipo que inventó Ángela Ruiz de la enciclopedia mecánica y hay dos grabaciones de voz que se inician automáticamente y relatan la historia de esta mujer olvidada.

También se pueden encontrar algunos poemas electrónicos que aluden y tratan de diferentes formas la maternidad: "Maternidad temprana" 
"A mother's pause" "Bio Data Matter". Mientras que, por un lado, en "A mother's pause" se muestra un procesador de texto en el que hay escrito en mayúsculas la palabra maternidad en inglés, por otro lado, en "Bio Data Matter" aparece justamente esa imagen del procesador de texto con la misma palabra, pero superpuesta sobre la imagen de una pared que tiene pintada la siguiente frase: "puta big data". A su vez, en una esquina de la pantalla hay un video de YouTube que se reproduce automáticamente en el Alex Saum intenta hablar de la relación entre la maternidad y el software.

"Sinfonía Documental" es un poema especialmente interesante, puesto que al iniciar el poema el lector se encuentra con una pantalla de fondo blanco en la que hay una serie letras que repiten, desacompasadas, el mismo texto en el que, como si de un anuncio comercial se tratase, Saum insta al lector a documentar su vida en las redes sociales, a poner fotos de su perro, gato, hija, marido o del día de la madre, y en esta última palabra se descompone y hace formaciones con las letras de madre. Todo esto se desarrolla mientras suena en bucle diferentes sonidos de redes sociales, como la melodía de llamada de Skype, el sonido de estas plataformas cuando se manda o se recibe un mensaje escrito por el chat, el silbido de Twitter, así como los sonidos de inicio del sistema operativo Windows. De esta forma, en la serie de poemas electrónicos WOMEN \& CAPITALISM, Saum combina selfies, GIFs, capturas de pantalla, grabaciones y el uso de diferentes plataformas y redes sociales para crear poemas electrónicos.

Como se ha podido comprobar al analizar la poesía electrónica de Belén Gache y Alex Saum, ambas poetas coinciden en varias características de su e-poesía como son la explotación de elementos multimedia, la intertextualidad y el collage, el carácter lúdico y, por supuesto, el uso y aprovechamiento de los medios informáticos y digitales. Aun así, cabe destacar las diferencias de ambas poetas, ya que mientras que en las obras de Gache se le ofrece al lector un mayor nomadismo y un grado superior de implicación con las diferentes formas de interactuar con los poemas, en la obra de Alex Saum hay un mayor aprovechamiento de las herramientas libres y gratuitas que ofrece internet y que resultan muy conocidas y 
actuales al lector; es el caso, por ejemplo, de plataformas como YouTube, páginas de información como la Wikipedia o toda una serie de redes sociales como Skype e Instagram entre otras. El análisis y contraste de las obras poéticas de ambas escritoras muestra la riqueza y variedad que existe en la e-poesía y ya que no hay una definición concreta y exacta sobre la literatura y poesía electrónica, como se expuso al inicio de este artículo, de igual forma no hay una manera concreta y única de hacer e-poesía.

\section{REFERENCIAS BIBLIOGRÁFICAS}

ADELL, J. E. (2004). "Poéticas electrónicas: una aproximación al estudio semiótico de la e-poesía”. En Arte y nuevas tecnologías: X Congreso de la Asociación Española de Semiótica, Miguel Ángel Muro Munilla (coord.), 138-148. La Rioja: Universidad de La Rioja.

BOOTZ, P. (1999). “Ai-je lu ce text?”. En Littérature, Informatique, Lectures, Alexandre Vuillemin (ed), 245-274. Limoge: Pulim. (2006). "Les Basiques: la littérature numérique". En https://www. olats.org/livresetudes/basiques/litteraturenumerique/basiquesLN. php [07/03/2018].

BORRÁS CASTANYER, L. (2005). "Teorías literarias y retos digitales". En Textualidades electrónicas. Nuevos escenarios para la literatura, Laura Borrás Castanyer (ed.), 23-78. Barcelona: Editorial UOC.

CORRAL CAÑAS, C. (2015). "Gigantes digitales. Quijote en 17000 tuits de Diego Buendía y Escribe tu propio Quijote de Belén Gache”. Caracteres. Estudios culturales y criticos de la esfera digital, http:// revistacaracteres.net/revista/vol4n1mayo2015/gigantesdigitales/ [18/04/2018].

ELECTRONIC LITERATURE ORGANIZATION. "What is E-Lit". Electronic Literature Organization, https://eliterature.org/about/ [23/03/2018]. 
ENBERG, M. \& BOLTER, J. D. (2011). "Digital Literature and the Modernist Problem" Digital Humanities Quarterly, 5.3. http:// digitalhumanities.org:8081/dhq/vol/5/3/000099/000099.html [25/03/2018].

GACHE, B. (2006). Wordtoys. http://www.findelmundo.com.ar/wordtoys/ [22/04/2018].

(2011). Góngora Wordtoys. http://belengache.net/gongorawordtoys/ [26/04/2018].

GAÍNZA, C. (2014). “Campos literarios emergentes: literatura digital en América Latina". Estudios Avanzados (Santiago de Chile: Universidad Santiago de Chile) 22, 29-43, http://www.revistas. usach.cl/ojs/index.php/ideas/article/view/1871 [12/04/2018].

IRIGARAY, L. (1985). This sex which is not one. N.York: Cornell University Press.

KOSKIMAA, R (2010). “Teaching Digital Literature: Code and Culture". En Teaching Literature at a Distance: Open, Online and Blended Learning, Takis Kayalis y Anastasia Natsina (eds.), 123-136. Londres: Continuum International Publishing Group,

KRIEGER OLINTO, H. (2012). "Literatura digital, una nueva relación entre teoría y práctica experimental". En Ciberliteratura y comparatismo, Rafael Alemany Ferrer y Francisco Chico Rico (eds.), 181-189. Alicante: Universitat de Alacant / Sociedad Española de Literatura General y Comparada.

MOLINUEVO, J. L. (2006). La vida en tiempo real. La crisis de las utopías digitales. Madrid: Biblioteca Nueva.

REGUEIRO SALGADO, B. (2012). “¿Qué es poesía?: la literalidad en la poesía digital”. En Ciberliteratura y comparatismo, Rafael Alemany Ferrer y Francisco Chico Rico (eds.), 233-248. Alicante: Universitat de Alacant / Sociedad Española de Literatura General y Comparada.

SÁNCHEZ-MESA, D. (2010). "Entre colonos e inmigrantes. Nuevos límites de la literatura comparada en la cibercultura". En Actas del 
XVII Simposio de la Sociedad Española de Literatura General y Comparada, Montserrat Cots Vicente y Antonio Monegal (coords.), vol. 1, 135-146. Barcelona: Universidad Pompeu i Fabra.

SAUM-PASCUAL, A. (2015). 'Creative work. \#SELFIEPOETRY'. http:// www.alexsaum.com/selfiepoetry/ [25/04/2018].

(2017). "Teaching Electronic Literature as Digital Humanities:

A Proposal". Digital Humanities Quarterly 11.3, http://www. digitalhumanities.org/dhq/vol/11/3/000314/000314.html [07/04/2018].

\#SELFIEPOETRY: Fake Art Histories \& the Inscription of the Digital Self. http://newhive.com/alexsaum/about-selfiepoetry [22/04/2018].

WOMEN \& CAPITALISM. http://newhive.com/selflex/aboutselfiepoetry-vol-2 [28/04/2018].

VUILLEMIN, A. (2005). "Poesía, informática y creación: las nuevas aproximaciones". En Textualidades electrónicas. Nuevos escenarios para la literatura, Laura Borrás Castanyer (ed.), 163175. Barcelona: Editorial UOC.

Recibido el 15 de mayo de 2018.

Aceptado el 2 de julio de 2018. 